\title{
Coordinative Stabilization of a Phosphido-phosphinidene Ligand
}

\author{
Otto J. Scherer, * Rainer Winter and Gotthelf Wolmershäuser \\ Fachbereich Chemie, Universität Kaiserslautern, Postfach 30 49, W-6750 Kaiserslautern, Germany
}

The phosphido-phosphinidene coordination mode $\mathrm{C}$ of a $\mathrm{P}_{2}$ ligand has been realized in the trinuclear complex $\left[(T a L)_{3}\left(P_{4}\right)\left(P_{2}\right)\right] 2\left(L=1,3-B_{2}{ }_{2} C_{5} H_{3}\right)$; structural proof was obtained by $X$-ray structure determination of the $\left[(\mathrm{TaL})_{3}\left(\mathrm{P}_{4}\left\{\mathrm{Fe}(\mathrm{CO})_{4}\right\}\right)\left(\mathrm{P}_{2}\right)\right]$ derivative 3.

The novel coordination mode of a $\mathrm{P}_{2}$-unit ${ }^{1}$ as phosphidophosphinidene ligand $\mathbf{B}$ may be visualized by formally replacing the two hydrogen atoms of the phosphino-phosphinidene $\mathrm{P}_{2} \mathrm{H}_{2}$ isomer $\mathbf{A}^{2}$ by two transition metal complex fragments.

We have now prepared the complexes 2 and $3+$ in 35 and $32 \%$ yields, respectively, by a procedure described in Scheme 1. Both contain trinuclear cluster cores with the phosphinidene $\mathbf{P}$ atom of the phosphido-phosphinidene ligand ${ }^{3}$ of $\mathbf{B}$ being further terminally coordinated to a third transition metal fragment as shown in $\mathbf{C}$. The $\mathrm{P}_{2}$ ligand thus acts as a four-electron donor, a coordination mode slightly different to that found independently by Nixon's group in the trirutheniumnonacarbonyl complex $\left[\mathrm{Ru}_{3}(\mathrm{CO})_{9}\left(\mathrm{P}_{5} \mathrm{C}_{5} \mathrm{Bu}^{\mathrm{t}_{5}}\right)\right] .{ }^{4} \mathrm{Com}-$ plex 2 is obtained as a brown-green microcrystalline powder or as small square crystals, which did, however, not diffract.

Compound 3 forms yellow-green crystals which are sparingly soluble in light petroleum, moderately soluble in benzene and toluene and readily soluble in dichloromethane. Both compounds are slightly susceptible to moisture or air.

Remarkable features of the 31 P NMR data are the pronounced low field shift, characteristic for a bent phosphinidene phosphorus atom ${ }^{3}[\delta 698.8$ for 2 and 701.9 for $P(1)$ of 3$]$ and the extreme high field shift of the phosphorus atom at the apex of the pyramidal $\mathrm{P}_{4}$ unit $[\delta-455.0$ for 2 and -466.0 for $\mathrm{P}(3)$ of

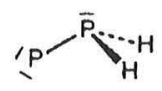

A

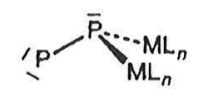

B

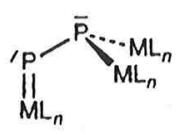

c

\footnotetext{
$\dagger$ In the complexation reaction two further isomers are formed in an approximate $1: 1$ ratio and a total yield of about $10 \%$, one with a single $\left\{\mathrm{Fe}(\mathrm{CO})_{4}\right\}$ group attached to the $\mathrm{P}_{2}$ unit and the other one with two $\left\{\mathrm{Fe}(\mathrm{CO})_{4}\right\}$ groups. Separation by means of column chromatography has not yet been successful.
}

3]; shift values, which are close to that of white phosphorus, $P_{4}$, itself $(\delta-522)$.

Fig. 1 represents the molecular structure of 3 as established by an X-ray structure analysis. $\S \mathrm{The} \mathrm{Ta}_{3} \mathrm{P}_{6}$-framework consists of an almost isosceles $\mathrm{Ta}_{3}$-triangle $[\mathrm{Ta}(1)-\mathrm{Ta}(2)=$ 2.936(2), $\mathrm{Ta}(1) \cdots \mathrm{Ta}(3)=3.156(2)$ and $\mathrm{Ta}(2) \cdots \mathrm{Ta}(3)=$ $3.125(2) \AA$ ], which is capped by a $P_{2}$ phosphido-phosphinidene ligand on one side and a pyramidal $\mathrm{P}_{4}$ unit on the other. Thus, the cluster core of 3 can be described as a severely distorted $\mathrm{Ta}_{3} \mathrm{P}_{5}$ cubane where the $\mathrm{P}(2)$ atom of the phosphido-

\# ${ }^{31} \mathrm{P}$ NMR data $\left(\mathrm{C}_{6} \mathrm{D}_{6}\right.$, chemical shifts in ppm) $2: \delta 698.8\left(\mathrm{~d}, J_{\mathrm{P}, \mathrm{P}} 465\right.$ $\mathrm{Hz}, 1 \mathrm{P}), 250.5$ (d, $\left.J_{\mathrm{P} . \mathrm{P}} 359 \mathrm{~Hz}, 2 \mathrm{P}\right), 156.8$ (dd, $J_{\mathrm{P}, \mathrm{P}} 344,2 J_{\mathrm{P}, \mathrm{P}} 14 \mathrm{~Hz}$ $1 \mathrm{P}),-32.9\left(\mathrm{dd}, J_{\mathrm{P} . \mathrm{P}} 465,{ }^{2} J_{\mathrm{P} . \mathrm{P}} 14 \mathrm{~Hz}, 1 \mathrm{P}\right),-455.0\left(\mathrm{dt}, J_{\mathrm{P} . \mathrm{P}} 359\right.$ and 344 $\mathrm{Hz}, 1 \mathrm{P})$.

3: $\delta 701.9\left[\mathrm{~d}, J_{\mathrm{P}} \mathrm{P} 475 \mathrm{~Hz}, \mathrm{P}(1)\right], 292.2\left[\mathrm{~d}, J_{\mathrm{P}, \mathrm{P}} 364 \mathrm{~Hz}, \mathrm{P}(6)\right], 234.7$ $\left[\mathrm{d}, J_{\mathrm{P}, \mathrm{P}} 354 \mathrm{~Hz}, \mathrm{P}(5)\right], 143.9\left[\mathrm{~d}, J_{\mathrm{P}, \mathrm{P}} 341 \mathrm{~Hz}, \mathrm{P}(4)\right],-25.8\left[\mathrm{~d}, J_{\mathrm{P}, \mathrm{P}} 475\right.$ $\mathrm{Hz}, \mathrm{P}(2)$ ],-466.0 [ddd, $J_{\mathrm{P}, \mathrm{P}} 364,354$ and $341 \mathrm{~Hz}, \mathrm{P}(3)$ ].

${ }^{1} \mathrm{H}$ NMR data $2\left(\mathrm{C}_{7} \mathrm{D}_{8}, T=273 \mathrm{~K}\right): \delta 6.44(\mathrm{~m}, 2 \mathrm{H}), 5.98(\mathrm{~m}, 2 \mathrm{H})$, $5.45(\mathrm{~m}, 2 \mathrm{H}), 5.43(\mathrm{~m}, 1 \mathrm{H}), 4.74(\mathrm{~m}, 2 \mathrm{H}), 1.56(\mathrm{~s}, 18 \mathrm{H}), 1.49(\mathrm{~s}, 18 \mathrm{H})$, $1.14(\mathrm{~s}, 18 \mathrm{H})$

$3\left(\mathrm{C}_{6} \mathrm{D}_{6}, T=298 \mathrm{~K}\right): \delta 6.70(\mathrm{~m}, 2 \mathrm{H}), 6.50(\mathrm{~m}, 1 \mathrm{H}), 6.01(\mathrm{~m}, 1 \mathrm{H})$, $5.55(\mathrm{~m}, 2 \mathrm{H}), 5.09(\mathrm{~m}, 1 \mathrm{H}), 4.89(\mathrm{~m}, 1 \mathrm{H}), 4.23(\mathrm{~m}, 1 \mathrm{H}), 1.45(\mathrm{~s}, 9 \mathrm{H})$, $1.35(\mathrm{~s}, 9 \mathrm{H}), 1.25(\mathrm{~s}, 9 \mathrm{H}), 0.91(\mathrm{~s}, 9 \mathrm{H}), 0.87(\mathrm{~s}, 9 \mathrm{H}), 0.67(\mathrm{~s}, 9 \mathrm{H})$ $\mathrm{v}(\mathrm{CO}) / \mathrm{cm}^{-1}$ in light petroleum: $2039 \mathrm{vs}, 1969 \mathrm{~m}, 1946 \mathrm{~s}, 1927 \mathrm{~s}$; in $\mathrm{KBr}$ : 2035vs, 1962m, 1940s, 1923s.

§ Crystal data for 3: $\mathrm{C}_{43} \mathrm{H}_{63} \mathrm{O}_{4} \mathrm{P}_{6} \mathrm{FeTa}_{3} \cdot c a \cdot 0.75 \mathrm{CH}_{2} \mathrm{Cl}_{2}$. Orthorhombic, space group $F d d 2, a=32.883(3), b=40.815(5), c=17.078(2) \AA$, $V=22920(4) \AA^{3}, D_{\mathrm{c}}=1.70 \mathrm{~g} \mathrm{~cm}^{-3}$, max residual electron density 1.55 e $\AA^{-3} .5814$ unique reflections were recorded, 3787 of which were 'observed' with $I>2.0 \sigma(I)(\omega-2 \theta$ scan) using Mo-K $\alpha$ radiation $(\lambda=$ $0.71073 \AA$ ), graphite monochromator, on an Enraf-Nonius CAD4 diffractometer.

Solution by SHELXS 86 and refinement by SHELX 76. $R\left(R_{\mathrm{w}}\right)=$ $0.076(0.080)$. The high residual electron density is due to incorporated solvent $\left(\mathrm{CH}_{2} \mathrm{Cl}_{2}\right)$ residing at $x / a=0.298, y / b=0.368, z / c=0.402$ and on a twofold axis $x / a=y / b=0, z / c=-0.479$. Both positions are populated to about $50 \%$. Additional disorder of the solvent hampered their inclusion into structural refinement.

Atomic coordinates, bond lengths and angles, and thermal parameters have been deposited at the Cambridge Crystallographic Data Centre. See Notice to Authors, Issue No. 1. 


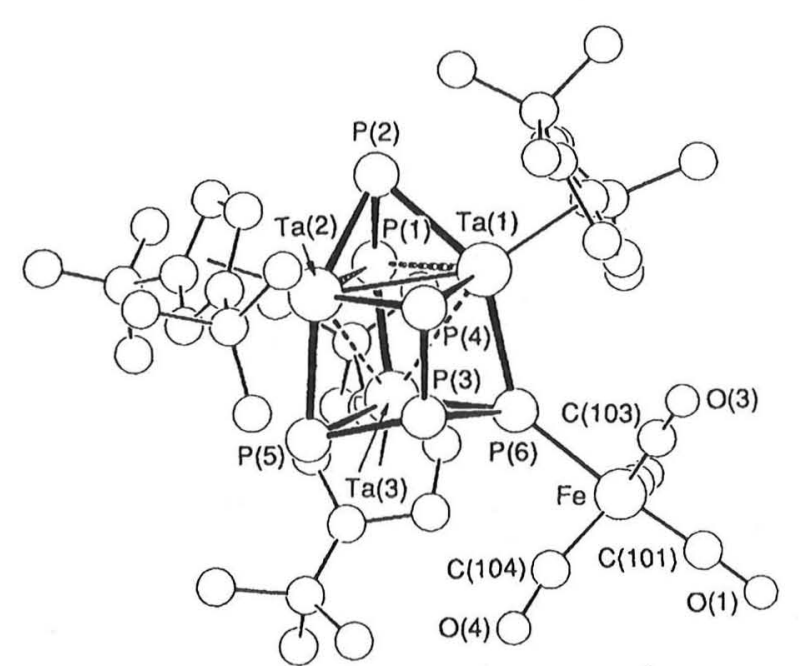

Fig. 1 Molecular structure of 3. Selected bond lengths $(\AA)$ and angles $\left(^{\circ}\right)$. P(1)-P(2) 2.088(15), P(3)-P(4) 2.170(15), P(3)-P(5) 2.203(15), $\mathrm{P}(3)-\mathrm{P}(6) 2.226(16), \mathrm{P}(1) \cdots \mathrm{Ta}(1) 2.681(11), \mathrm{P}(1) \cdots \mathrm{Ta}(2) 2.728(11)$, $\mathrm{P}(1)-\mathrm{Ta}(3)$ 2.328(11), $\mathrm{P}(2)-\mathrm{Ta}(1) 2.497(11), \mathrm{P}(2)-\mathrm{Ta}(2) 2.500(11)$, $\mathrm{P}(4)-\mathrm{Ta}(1)$ 2.492(11), $\mathrm{P}(4)-\mathrm{Ta}(2)$ 2.482(11), $\mathrm{P}(5)-\mathrm{Ta}(2) 2.519(11)$, $\mathrm{P}(5)-\mathrm{Ta}(3)$ 2.407(12), $\mathrm{P}(6)-\mathrm{Ta}(1)$ 2.528(11), $\mathrm{P}(6)-\mathrm{Ta}(3) 2.398(11)$ $\mathrm{P}(3) \cdots \mathrm{Ta}(1) \quad 2.902(11), \quad \mathrm{P}(3) \cdots \mathrm{Ta}(2) \quad 2.837(11), \quad \mathrm{P}(3) \cdots \mathrm{Ta}(3)$ 2.816(11), $\quad \mathrm{Ta}(1)-\mathrm{Ta}(2) \quad 2.936(2), \quad \mathrm{Ta}(1) \cdots \mathrm{Ta}(3) \quad 3.156(2)$, $\mathrm{Ta}(2) \cdots \mathrm{Ta}(3)$ 3.125(2); $\mathrm{P}(2)-\mathrm{P}(1)-\mathrm{Ta}(3)$ 129.3(6).

phosphinidene ligand caps the slightly folded $\mathrm{P}(1), \mathrm{Ta}(2)$, $\mathrm{P}(4), \mathrm{Ta}(1)$ face (sum of angles $=357.8^{\circ}$ ) only by half (see Fig. 2).

Alternatively the cluster core of 3 may be viewed as a $\mathrm{Ta}_{3} \mathrm{P}_{6}$ homocubene, with the phosphinidene $\mathrm{P}$ atom $\mathrm{P}(1)$ bridging the $\mathrm{Ta}(3)-\mathrm{P}(2)$ edge of a $\mathrm{Ta}_{3} \mathrm{P}_{5}$ cubane. The pyramidal $\mathrm{P}_{4}$ unit of 3 can be envisaged as being directly related to the $P_{4}$ tetrahedron where three of its original six edges are still intact. The individual bond lengths of the remaining edges $[\mathrm{P}(3)$ $\mathrm{P}(4),(5),(6)=2.170(15), 2.203(15), 2.226(16) \AA]$ average at $2.20 \AA$, a value which is almost identical with that of $2.21 \AA$ found for the $\mathrm{P}_{4}$ molecule itself.

As shown by the P-P-P angles of 111.8(6) [P(4)-P(3)-P(5)], 109.5(6) $[\mathrm{P}(4)-\mathrm{P}(3)-\mathrm{P}(6)]$ and $108.8(6)^{\circ}[\mathrm{P}(5)-\mathrm{P}(3)-\mathrm{P}(6)]$ the pyramidal $\mathrm{P}_{4}$ unit is notably obtuse with respect to the parent molecule.

The Ta-P bond lengths within the cluster core of $\mathbf{3}$ can be divided into three groups: The shortest contact is found between the phosphinidene $\mathrm{P}$ atom $\mathrm{P}(1)$ and $\mathrm{Ta}(3)[2.328(11)$ $\AA]$. This accounts for some double bond character which is already suggested by the diamagnetism of this compound. All Ta-P bond distances including the three basal $\mathrm{P}$ atoms of the $\mathrm{P}_{4}$ unit and the capping $\mathrm{P}(2)$ atom of the phosphido-phosphinidene ligand lie within the range of $2.398(11)[\mathrm{Ta}(3)-\mathrm{P}(6)]$ to $2.528(11)[\mathrm{Ta}(1)-\mathrm{P}(6)] \AA$. By far the longest Ta-P distances are those between the $\mathrm{Ta}$ atoms $\mathrm{Ta}(1)$ and $\mathrm{Ta}(2)$ and the phosphinidene atom $\mathrm{P}(1)$ of the $\mathrm{P}_{2}$ ligand $[\mathrm{Ta}(1) \cdots \mathrm{P}(1)=$

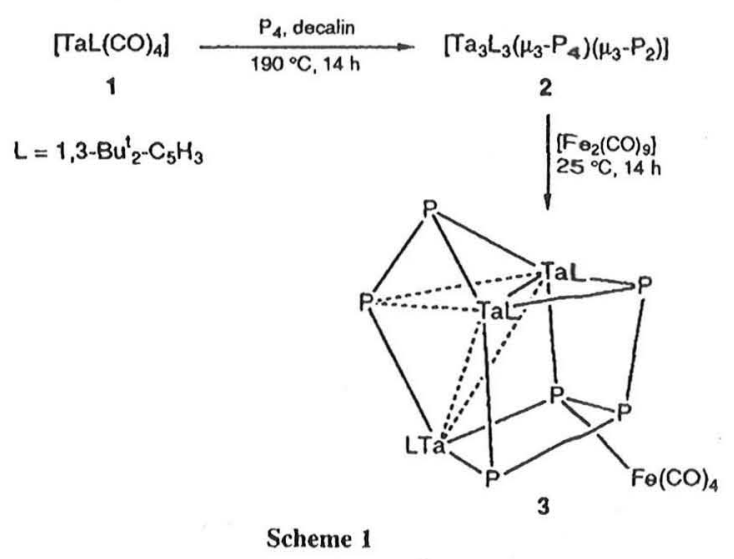

2.681(11), $\mathrm{Ta}(2) \cdots \mathrm{P}(1)=2.728(11) \AA]$. These long contacts are probably implicated by the cluster geometry of 3 .

In the bent phosphido-phosphinidene ligand a $\mathrm{P}(2)-\mathrm{P}(1)-$ $\mathrm{Ta}(3)$ bond angle of $129.3(6)^{\circ}$ is found. The $\mathrm{P}(1), \mathrm{P}(2), \mathrm{Ta}(1)$, $\mathrm{Ta}(2)$ subunit of 3 simulates a diphospha-dimetallatetrahedrane and the short $\mathrm{P}(1)-\mathrm{P}(2)$ bond length of $2.088(15) \AA$ lies well within the range found for other members of this class (2.019-2.154 $\AA$ ). ${ }^{1}$ Compound 2 possesses a $\mathrm{Ta}_{3} \mathrm{P}_{6}$ framework identical to that of 3 . The absence of the $\left\{\mathrm{Fe}(\mathrm{CO})_{4}\right\}$ group attached to it leads, however, to a higher degree of symmetry. Thus, a mirror plane through the bent $\mathrm{P}_{2} \mathrm{Ta}$ unit and the opposite edge of the pyramidal $\mathrm{P}_{4}$ ligand bisects the molecule as clearly indicated by NMR spectroscopy. $¥$

We wish to thank the 'Fonds der Chemischen Industrie' for financial support (grant for R. W.).

\section{References}

1 Recent reviews. O. J. Scherer, Angew. Chem., 1990, 102, 1137: Angew. Chem., Int. Ed. Engl., 1990, 29, 1104; M. Scheer and E. Herrmann, Z. Chem., 1990, 30, 41.

2 For theoretical studies, see: T. L. Allen, A. C. Scheiner, Y. Yamaguchi and H. F. Schaefer, III, J. Am. Chem. Soc, , 1986, 108 7579 , and references cited therein; for trapping reactions of $\mathrm{R}_{2} \mathrm{PP}$ see: G. Fritz, T. Vaahs, H. Fleischer and E. Matern, Angew. Chem., 1989, 101, 324; Angew. Chem., Int. Ed. Engl., 1989, 28 315: Z. Anorg. Allg. Chem., 1989, 570, 54. For studies on $\mathrm{R}_{2} \mathrm{PP}$ as ligand, see: G. Trinquier and G. Bertrand, Inorg. Chem., 1985, 24. 3842

3 For terminal RP ligands, see e.g. P. B. Hitchcock, M. F. Lappert and W. P. Leung, J. Chem. Soc., Chem. Commun., 1987, 1282; F. Mathey, Angew. Chem., 1987, 99, 285; Angew. Chem., Int. Ed. Engl., 1987, 26, 275; A. H. Cowley and A. R. Barron, Acc. Chem. Res., 1988, 21, 81; A. H. Cowley, B. Pellerin, J. L. Atwood and S. G. Bott, J. Am. Chem. Soc., 1990, 112, 6734; C. C. Cummins, R. R. Schrock and W. M. Davis, Angew. Chem., in the press: $\mathrm{R}_{2}$ NP: E. Niecke, J. Hein and M. Nieger, Organometallics, 1989, 8, 2290

4 R. Bartsch, P. B. Hitchcock and J. F. Nixon, J. Chem. Soc., Chem. Commun., 1993, preceding communication. 